\title{
PENGARUHKOMITMEN GURU DAN STRATEGI PEMBELAJARAN TERHADAP PRESTASI DAN MUTU SEKOLAH PADA SEKOLAH DASAR ISLAM TERPADU DI KABUPATEN SUMENEP
}

\author{
${ }^{1}$ Alvin Arifin \\ ${ }^{1}$ Universitas Bahaudin Mudhary Madura, Jl. Raya Lenteng No. 10 Sumenep, Indonesia \\ e-mail: alvinarifin@unibamadura.ac.id
}

\begin{abstract}
This study examines the effect of teacher commitment and learning strategies on school achievement and quality in integrated Islamic elementary schools in Sumenep district. This research is a quantitative study. Data collection techniques by giving questionnaires to teachers. The population of this research is all teachers who teach in integrated Islamic elementary schools in Sumenep Regency with a sample of 46 teachers. The analysis used is descriptive analysis and partial least square analysis with SmartPLS software. The results of this study indicate that teacher commitment and student achievement have a positive and significant effect on school quality. Learning strategies do not have a direct influence on school quality. Teacher commitment and learning strategies have a positive and significant effect on achievement. Achievement mediates the effect of teacher commitment on school quality significantly. Achievement does not mediate the effect of learning strategies on school quality.
\end{abstract}

Keywords: teacher commitment, learning strategies, student achievement, quality school

\section{PENDAHULUAN}

Mutu sekolah merupakan cerminan dari keberhasilan dari penerapan strategi dalam merumuskan metode pembelajaran yang berkualitas bagi siswanya. Setiap sekolah pastinya memiliki standar mutu guna menjaga kualitas pengajaran serta menghasilkan output yang berkualitas. Kualitas siswa dapat dilihat dari prestasi siswa tersebut. Sekolah dasar yang ditempuh selama 6 tahun merupakan pondasi pendidikan formal yang semestinya harus dijaga mutunya. Kurikulum merupakan perangkat serta program pembelajaran yang dirancang sebagai pegangan dalam menerapkan pembelajaran. Kurikulum yang diterapkan tentunya sama antar sekolah. Penerapan kurikulum yang sama antar sekolah sehingga dalam melihat kualitas pembelajaran ditentukan oleh strategi pembelajaran atau kreatifitas para guru dalam mengemas sebaikmungkin materi yang diberikan agar mudah dipahami siswanya.

Mutu sekolah merupakan salah satu gambaran pembelajaran dalam pengembangan sumber daya manusia yang ada di sekolah. Kualitas sumber daya manusia khususnya siswa yang merupakan masalah yang umumnya terjadi di setiap sekolah. Ada ketimpangan kualitas antar para siswa sehingga perlu adanya sinergi antara sekolah dan siswa guna menghasilkan output yang kualitasnya merata sehingga berdampak pada mutu sekolah. Basis mutu sekolah yang baik berfokus pada penyediaan layanan pendidikan yang 
berkualitas tinggi guna menarik minat siswa untuk belajar ${ }^{1}$. Mutu sekolah yang baik didukung bukan hanya program pembelajarannya tetapi juga fasilitas yang disediakan, serta adanya guru-guru yang berkualitas ${ }^{2}$. Sekolah yang memiliki mutu yang baik juga pastinya akan memberikan manfaat pada siswa, orang tua siswa, guru, dan juga masyarakat ${ }^{3}$.

Indikator dari mutu sekolah adalah sebagai berikut: (1) Kualitas proses belajar mengajar, yaitu penyampaian materi pembelajaran yang didukung kemampuan guru yang baik. (2) Manajemen sekolah, yaitu mempersiapkan sumber daya manusia yang baik yaitu siswa dalam menghadapi tantangan masa depan. (3) Iklim sekolah, yaitu sekolah memiliki atmosfer dimana siswanya dapat menyampaikan ide dan gagasantanpa rasa takut. (4) Teknologi, sekolah memberikan pembelajaran berbasis teknologi sehingga membuat siswa dapat beradaptasi dengan kemajuan zaman. (5) Ukuran kelas, yaitu ukuran kelas yang kondusif untuk tempat siswa belajar dengan tidak berdesakan dan tidak pengap. (6) Disiplin, yaitu kepatuhan siswa terhadap tata tertib sekolah guna menjaga norma dan kondusifitas proses belajar mengajar ${ }^{4}$.

Komitmen guru merupakan kesungguhan guru dalam pemberian pengajaran kepada siswa, pengembangan karir untuk diri sendiri, serta professional dalam menjalankan tugas sekolah $^{5}$. Komitmen guru juga dapat dianggap sebagai cerminan guru terkait profesionalitas guru'. Profesionalitas seorang guru ditunjukkan bagaimana mereka menjalankan profesinya dengan sebaik mungkin. Sebagai garda terdepan dalam mencerdaskan bangsa, guru merupakan profesi mulia yang tentunya tidak bisa hanya dianggap sebatas profesi dalam mencari penghidupan tetapi juga perlunya komitmen dalam menyebarkan pengetahuan dengan sebaik mungkin. Guru yang memiliki komitmen

\footnotetext{
${ }^{1}$ Hulya Senol and Gokmen Dagli, 'Increasing Service Quality in Education: Views of Principals and Teachers', Eurasia Journal of Mathematics, Science and Technology Education, 13.8 (2017), 4857-71.

${ }^{2}$ Manas Ranjan Panigrahi, 'School Effectiveness at Primary Level of Education in Relation to Classroom Teaching’, International Journal of Instruction, 7.2 (2014), 51-64.

${ }^{3} \mathrm{~V}$. A Haseena and Ajims. P Mohammed, 'Aspects of Quality in Education for the Improvement of Educational Scenario', Journal of Education and Practice, 6.4 (2015), 100-106.

${ }^{4}$ Sanjay Mehra, 'Criteria of Quality School Education', 2018, 665-68.

${ }^{5}$ Mustafa Altun, 'The Effects of Teacher Commitment on Student Achievement', International Journal of Social Sciences \& Educational Studies, 3.3 (2017).

${ }^{6}$ Ogunlade Joseph Olurotimi, Kamonges Wahab Asad, and Abdulkadir Abdulrauf, 'Motivational Factors and Teachers Commitment in Public Secondary Schools in Mbale Municipality', Journal of Education and Practice, 6.15 (2015), 117-23.
} 
cenderung melakukan pengajaran efektif yang dibutuhkan untuk membangun sinergi antara guru dan siswa agar apa yang dipelajari dapat dicerna dengan baik oleh siswa ${ }^{7}$.

Indikator komitmen guru adalah sebagai berikut: (1) Afektif, yaitu kesediaan untuk tetap dengan pekerjaannya dikarenakan keyakinan bahwa peran dan deskripsi pekerjaan jelas. (2) Berkelanjutan, yaitu tidak ada keinginan untuk meninggalkan pekerjaan yang sudah ada untuk mencari pekerjaan yang baru. (3) Normatif, yaitu keinginan untuk tetap bekerja di tempat tersebut dikarenakan sudah merasa sebagai kewajiban yang harus diemban ${ }^{8}$.

Strategi pembelajaran tidak sertamerta sama antar sekolah. Melihat karakteristik siswa serta lingkungan sekolah yang tetntunya memiliki perbedaan. Penyamaan strategi pembelajaran tentunya akan menyulitkan sekolah, guru maupun siswa melihat keterbatasan sumber daya yang ada di masing-masing sekolah.

Strategi pembelajaran merupakan metode terbaik yang digunakan guru untuk menghasilkan pembelajaran yang efektif dan efisien. Strategi pembelajaran merupakan proses jangka panjang yang berorientasi masalah guna mengasah siswa dalam menghadapi masalah dalam proses pembelajaran ${ }^{9}$. Strategi pembelajaran dapat dilakukan dengan cara yang sama atau cara yang berbeda dalam proses pembelajaran mengikuti karakteristik siswa ${ }^{10}$. Strategi pembelajaran yang diterapkan disesuaikan dengan situasi pembelajaran masa kini sehingga adaptasi lingkungan Pendidikan berjalan dengan baik ${ }^{11}$. Cara terbaik yang digunakan guna menyampaikan materi pembelajaran kepada siswa agar mudah dipahami merupakan strategi pembelajaran. Strategi pembelajaran mengikuti karakteristik siswa juga mengikuti perkembangan metode pembelajaran yang ada saat ini.

Indikator strategi pembelajaran adalah sebagai berikut: (1) Diskusi, merupakan cara mengelola proses pembelajaran dengan menyajikan masalah untuk dipecahkan Bersamasama. (2) Memberikan tugas, merupakan penyajian materi kepada siswa untuk melakukan pekerjaan ataupun proyek. (3) Eksperimental, merupakan cara mengelola proses

${ }^{7}$ Çăgrı Tuğrul Mart, 'A Passionate Teacher: Teacher Commitment and Dedication to Student Learning', International Journal of Academic Research in Progressive Education and Development, 2.1 (2013), 2226-6348.

${ }^{8}$ Basilius Redan Werang and Anak Agung Gede Agung, 'Teachers' Job Satisfaction, Organizational Commitment, and Performance in Indonesia: A Study from Merauke District', International Journal of Development and Sustainability, 6.8 (2017), 700-711.

${ }^{9}$ Hong Shi, 'Learning Strategies and Classification in Education', Institute for Learning Styles Journal, 1 (2017), 24-36.

${ }^{10}$ Margarita Pino Juste and Beatriz Rodríguez López, 'Learning Strategies in Higher Education', International Journal of Learning, 17.1 (2010), 259-74.

${ }^{11}$ Saskia Kistner and others, 'Teaching Learning Strategies. The Role of Instructional Context and Teacher Beliefs', Journal for Educational Research Online, 7.1 (2015), 176-97. 
pembelajaran dengan melakukan kegiatan eksperimen sehingga tidak membatasi kreatifitas mereka. (4) Tanya jawab, merupakan cara yang digunakan untuk membuat siswa berpikir kritis, caranya dengan merangsang siswa untuk bertanya materi yang telah diberikan sehingga mereka dapat bertanya apa yang belum mereka pahami ${ }^{12}$.

Prestasi sekolah dasa rmerupakan hasil sekolah dalam penerapan strategi pembelajaran yang telah diterapkan. Prestasi sekolah merupakan cerminan mutu sekolah tersebut. Semakin baik prestasi sekolah maka semakin baik mutu sekolah. Persepsi masyarakat masih beranggapan sekolah dasar swasta masih kalah bagus dengan sekolah dasar negeri. Melihat sekolah dasar swasta khususnya berbasis Islam yang tidak kalah kualitasnya dengan sekolah dasar negeri sehingga persepsi tersebut mestinya perlu dihilangkan. Sistem pembelajaran global serta moderen yang diterapkan sama sehingga kualitas pembelajarannya sama.

Prestasi siswa dapat dilihat dari bagaimana mereka berkompetisi baik secara kelompok ataupun secara personal antar siswa. Iklim kompetisi yang baik membuat siswa memiliki kebanggaan atas kemampuan yang mereka dapat dalam sekolah ${ }^{13}$. Prestasi siswa tidak lepas dari kontribusi guru. Penguatan kompetensi siswa dengan mengasah kemampuan mereka merupakan hal yang efektif dalam peningkatan prestasi siswa. Prestasi siswa tidak lepas dari peran guru dalam menyiapkan metode pembelajaran yang dapat diterima, sehingga ilmu yang disampaikan melekat ${ }^{14}$.

Indikator dari prestasi siswa adalah sebagai berikut: (1) Kinerja siswa, yaitu hasil penilaian siswa sesuai dengan standar sekolah. (2) Mengajar dan belajar, yaitu siswa memiliki motivasi dalam belajar. (3) Dukungan untuk siswa, yaitu siswa memiliki kondisi serta latar belakang keluarga yang baik. (4) Hubungan interpersonal, yaitu keterampilan dan keaktifan siswa di kelas ${ }^{15}$.

Penelitian ini berfokus pada sekolah dasar Islam terpadu yang ada di Kabupaten Sumenep. Sehingga dapat dilihat walaupun sekolah swasta tetapi memiliki kualitas yang sama dengans ekolah negeri dengan menanamkan nilai-nilai agama di dalamnya. Tujuan

\footnotetext{
${ }^{12}$ Wisnu Nugroho Aji and Sri Budiyono, 'The Teaching Strategy of Bahasa Indonesia in Curriculum', International Journal of Active Learning, 3.2 (2018), 58-64.

${ }^{13}$ Fariha Gull and Shumaila Shehzad, 'Effects of Cooperative Learning on Students' Academic Achievement', Journal of Education and Learning, 9.3 (2015), 246-55.

${ }^{14}$ Krisztián Széll, 'Factors Determining Student Achievement', Hungarian Educational Researcch Journal, 3.3 (2013), 55-66.

${ }^{15}$ Zuzana Juščáková, ' 5 Th International Conference for Theory and Practice in Education Information and Education', in 5th International Conference for Theory and Practice in Education Information and Education, 2012.
} 
penelitian ini adalah: (1) Untuk mengetahui pengaruh langsung kurikulum terhadap mutu sekolah. (2) Untuk mengetahui pengaruh langsung strategi pembelajaran terhadap mutu sekolah. (3) Untuk mengetahui pengaruh tidak langsung kurikulum terhadap mutu sekolah melalui prestasi sekolah. (4) Untuk mengetahui pengaruh tidak langsung strategi pembelajaran terhadap mutu sekolah melalui prestasi sekolah.

Penelitian ini dilakukan di Sekolah Dasar Islam Terpadu di Kabupaten Sumenep. Prestasi siswa merupakan output yang dihasilkan siswa dalam memahami pembelajaran yang telah diberikan. Prestasisiswa juga dapat disebut hasil belajar merupakan kemampuan siswa dari hasil stimulus yang berasal dari lingkungan eksternal dan proses kognitif yang dilakukan oleh siswa ${ }^{16}$

\section{METODE}

Penelitian ini merupakan penelitian kuantitatif dengan menganilis pengaruh langsung dan tidak langsung antar variabel. Data penelitian diperoleh dari responden melalui kuisioner. Populasi dalam penelitian ini adalah seluruh guru pengajar Sekolah Dasar Islam Terpadu di Kabupaten Sumenep. Sampel penelitian ini adalah guru pengajar Sekolah Dasar Islam Terpadu yang ada di Sekolah Dasar Islam Terpadu Pulau Sapudi Kabupaten Sumenep sebanyak 46 guru.

Metede analisis yang digunakan pertama menggunakan analisis deskriptif. Analisis deskriptif digunakan untuk mengetahui karakteristik responden. Analisis kedua adalah menggunakan analisis jalur untuk mengetahui pengaruh langsung dan tidak langsungnya menggunakan Partial Least Square. Alat analisis yang digunakan adalah menggunakan Smart PLS.

\section{HASIL DAN PEMBAHASAN}

Hasil peneletian yang pertama adalah membahas hasil analisis deskriptif yang menggambarkan karakteristik responden adalah sebagai berikut:

Tabel 1. Jenis Kelamin Responden

\begin{tabular}{ccc}
\hline Kategori & Frekuensi & Persentase \\
\hline Laki-laki & 31 & $67 \%$ \\
Perempuan & 15 & $33 \%$ \\
\hline
\end{tabular}

Sumber: Hasil Analisis, 2020

${ }^{16}$ Riswanto, A., \& Aryani, S. Learning motivation and student achievement: description analysis and relationships both. International Journal of Counseling and Education, (2017). 
Dari hasil analisis deskriptif untuk kategori jenis kelamin responden menunjukkan guru dengan jenis kelamin laki-laki sebanyak 31 orang dengan persentase $67 \%$. Guru dengan jenis kelamin perempuan sebanyak 15 orang dengan persentase $33 \%$.

Tabel 2. Pendidikan Terakhir Responden

\begin{tabular}{ccc}
\hline Kategori & Frekuensi & Persentase \\
\hline S1 & 41 & $89 \%$ \\
>S1 & 5 & $11 \%$ \\
\hline
\end{tabular}

Sumber: Hasil Analisis, 2020

Dari hasilanalisis deskriptif untuk kategori pendidikan terakhir responden menunjukkan guru dengan pendidikan terakhir S1 sebanyak 41 orang dengan persentase $89 \%$. Guru dengan pendidikan di atas S1 sebanyak 5 orang dengan persentase $11 \%$.

Analisis yang kedua adalah analisis Partial Least Square adalah sebagai berikut:

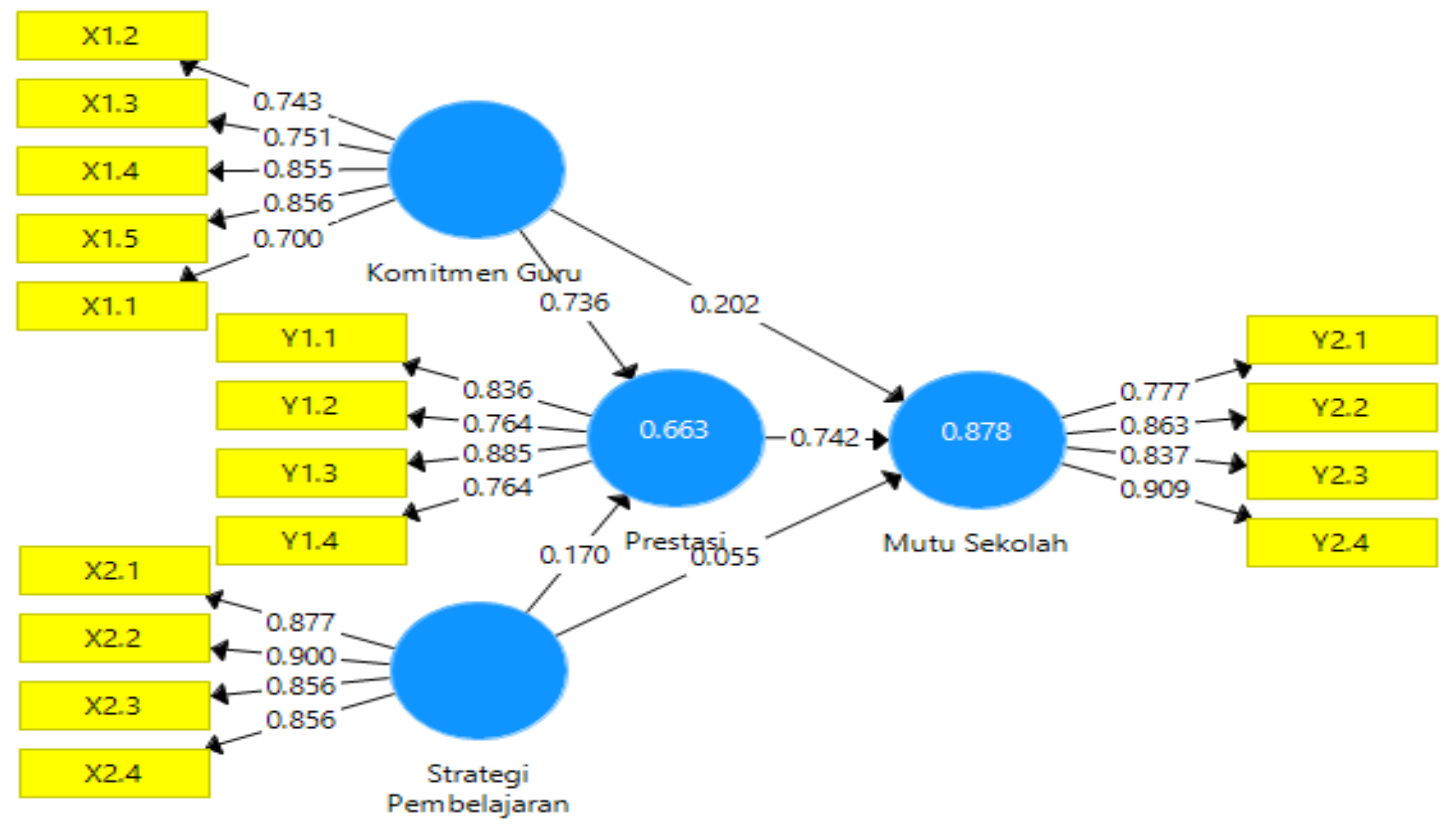

Gambar 2. Hasil Analisis Smart PLS 
Analisis uji validitas untuk menguji instrument penelitian apakah bisa digunakan sebagai landasan penelitian adalah sebagai berikut:

Tabel 3. Outer Loadings

\begin{tabular}{lcc}
\hline Variabel & Indikator & Outer Loadings \\
\hline Komitmen Guru (X1) & X1.1 & 0.700 \\
X1.2 & 0.743 \\
X1.3 & 0.751 \\
X1.4 & 0.855 \\
X1.5 & 0.856 \\
\hline StrategiPembelajaran (X2) & X2.1 & 0.877 \\
& X2.2 & 0.900 \\
X2.3 & 0.856 \\
Prestasi (Y1) & X2.4 & 0.856 \\
& Y1.1 & 0.836 \\
& Y1.3 & 0.764 \\
& Y1.4 & 0.885 \\
& Y2.1 & 0.764 \\
\hline MutuSekolah (Y2) & Y2.2 & 0.777 \\
& Y2.3 & 0.863 \\
& Y2.4 & 0.837 \\
& & 0.909
\end{tabular}

Sumber: Hasil Analisis, 2020

Hasil analis outer loadings menunjukkan bahwa output yang dihasilkan > 0,5 sehingga indikator-indikator dalam penelitian dapat digunakan untuk mengukur variabel penelitian.

Hasil uji reliabilitas untuk menguji kehandalan variabel yang digunakan dalam penelitian ini. Hasil uji reliabilitas adalah sebagai berikut:

Tabel 4. Uji Reliabilitas

\begin{tabular}{llll}
\hline \multicolumn{1}{c}{ Variabel } & \multicolumn{1}{c}{$\begin{array}{c}\text { Composite } \\
\text { Reliability }\end{array}$} & Cronbach's Alpha & AVE \\
& 0.887 & 0.842 & 0.614 \\
\hline Komitmen Guru (X1) & 0.927 & 0.899 & 0.761 \\
StrategiPembelajaran (X2) & 0.829 & 0.663 \\
Prestasi (Y1) & 0.887 & 0.869 & 0.719 \\
MutuSekolah (Y2) & 0.911 & & \\
\hline
\end{tabular}

Sumber: Hasil Analisis, 2020 
Dari hasil uji reliabilitas menunjukkan output yang sudah sesuai kriteria sehingga variabel-variabel tersebut reliabel dan dapat digunakan.

Hasil uji validitas dan reliabilitas menunjukkan variabel valid dan reliabel sehingga dapat dilakukan uji kausalitas atau uji pengaruh. Dari uji pengaruh kemudian dapat diuji hipotesis penelitian ini. Kriteria uji kausalitas adalah apabila pengaruh langsung menunjukkan hasil t-statistik lebih besar dari nilai t-tabel $(\mathrm{t}$-tabel $=1,96)$ maka hubungan variabel signifikan.

Hasil uji kausalitas (pengaruh langsung) adalah sebagai berikut:

Tabel 5. Uji Pengaruh Langsung

\begin{tabular}{llllll}
\hline \multicolumn{1}{c}{ Variabel } & $\begin{array}{l}\text { Original } \\
\text { Sample }\end{array}$ & $\begin{array}{l}\text { Sample } \\
\text { Mean }\end{array}$ & $\begin{array}{l}\text { Standard } \\
\text { Deviation }\end{array}$ & T-Statistics & $\begin{array}{l}\text { P- } \\
\text { Values }\end{array}$ \\
\hline $\begin{array}{l}\text { Komitmen Guru -> Mutu } \\
\text { Sekolah }\end{array}$ & 0.202 & 0.216 & 0.093 & 2.181 & 0.030 \\
$\begin{array}{l}\text { StrategiPembelajaran -> } \\
\text { Mutu Sekolah }\end{array}$ & 0.055 & 0.047 & 0.073 & 0.748 & 0.455 \\
$\begin{array}{l}\text { Komitmen Guru -> } \\
\text { Prestasi }\end{array}$ & 0.736 & 0.737 & 0.076 & 9.659 & 0.000 \\
$\begin{array}{l}\text { Strategi Pembelajaran -> } \\
\text { Prestasi }\end{array}$ & 0.170 & 0.175 & 0.085 & 2.012 & 0.045 \\
$\begin{array}{l}\text { Prestasi ->Mutu Sekolah } \\
\quad 0.742\end{array}$ & 0.739 & 0.092 & 8.029 & 0.000 \\
\hline
\end{tabular}

Sumber: Hasil Analisis, 2020

Komitmen guru berpengaruh langsung terhadap mutu sekolah signifikan. Semakin tinggi komitmen guru maka semakin tinggi pula mutu sekolah. Hasil ini menunjukkan bahwa hipotesis ke-1 diterima.

Strategi pembelajaran tidak berpengaruh langsung terhadap mutu sekolah. Semakin baik strategi pembelajaran yang dilakukan oleh para guru tidak ada pengaruhnya terhadap mutu sekolah. Hasil ini menunjukkan bahwa hipotesis ke-2 ditolak.

Komitmen guru berpengaruh positif dan signifikan terhadap prestasi. Semakin tinggi komitmen guru maka semakain baik prestasi siswa. Hasil ini menunjukkan bahwa hipotesis ke-3 diterima.

Strategi pembelajaran berpengaruh positif dan signifikan terhadap prestasi siswa. Semakin baik strategi pembelajaran yang dilakukan maka semakin baik prestasi siswa. Hasil ini menunjukkan bahwa hipotesis ke-4 diterima. 
Prestasi berpengaruh positif dan signifikan terhadap mutu sekolah. Semakin tingi prestasi siswa merupakan cerminan baiknya mutu sekolah tersebut. Hasil ini menunjukkan bahwa hipotesis ke-5 diterima.

Dari hasil uji kausalitas adalah sebagai berikut

Tabel 5. Uji Pengaruh Langsung

\begin{tabular}{lccccc}
\hline \multicolumn{1}{c}{ Variabel } & $\begin{array}{l}\text { Original } \\
\text { Sample }\end{array}$ & $\begin{array}{l}\text { Sample } \\
\text { Mean }\end{array}$ & $\begin{array}{l}\text { Standard } \\
\text { Deviation }\end{array}$ & T-Statistics & $\begin{array}{l}\text { P- } \\
\text { Values }\end{array}$ \\
\hline $\begin{array}{l}\text { Komitmen Guru -> Mutu } \\
\text { Sekolah }\end{array}$ & 0.546 & 0.543 & 0.079 & 6.877 & 0.000 \\
$\begin{array}{l}\text { Strategi Pembelajaran - } \\
\text { Mutu Sekolah }\end{array}$ & 0.126 & 0.131 & 0.068 & 1.846 & 0.065 \\
\hline
\end{tabular}

Sumber: Hasil Analisis, 2020

Hasil uji kausalitas pengaruh tidak langsung menunjukkan prestasi kerja memediasi pengaruh komitmen guru terhadap mutu sekolah secara signifikan. Semakin tinggi komitmen guru yang disertai prestasi siswa yang baik akan meningkatkan mutu sekolah. Hasil ini menunjukkan hipotesis ke-6 diterima.

Sedangkan prestasi tidak memediasi pengaruh strategi pembelajaran terhadap mutu sekolah. Semakin tinggi prestasi tidak adanya pengaruhnya terhadap strategi pembelajaran terhadap mutu sekolah. Hasil ini menunjukkan hipotesis ke-7 ditolak.

\section{KESIMPULAN DAN SARAN}

Hasil penelitian ini dapat disimpulkan sebagai berikut: (1) Komitmen guru berpengaruh langsung postif dan signifikan terhadap mutu sekolah. (2) Strategi pembelajaran tidak berpengaruh langsung terhadap mutu sekolah. (3) Komitmen guru berpengaruh langsung positif dan signifikan terhadap prestasi. (4) Strategi pembelajaran berpengaruh langsung positif dan signifikan terhadap prestasi. (5) Prestasi berpengaruh langsung positif dan signifikan terhadap mutu sekolah. (6) Prestasi memediasi pengaruh tidak langsung komitmen guru terhadap mutu sekolah secara positif dan signifikan. (7) Prestasi tidak memediasi pengaruh tidak langsung strategi pembelajaran terhadap mutu sekolah. 
Saran yang dapat diberikan adalah sebagai berikut: (1) Sekolah sebaiknya menetapkan strategi pembelajaran yang sesuai dengan standar pendidikan yang modern. Hal ini dikarenakan strategi pembelajaran memiliki pengaruh yang signifikan terhadap prestasi kerja. (2) Sekolah sebaiknya menjaga komitmen guru dalam memberikan pembelajaran terbaik pada siswa. Hal ini dapat dilihat bahwa komitmen guru berpengaruh signifikan terhadap prestasi serta mutu pendidikan secara langsung maupun tidak langsung. (3) Bagi peneliti lain dapat meneliti variabel-variabel lain yang berpengaruh terhadap mutu pendidikan.

\section{DAFTAR RUJUKAN}

Aji, Wisnu Nugroho, and Sri Budiyono, 'The Teaching Strategy of Bahasa Indonesia in Curriculum', International Journal of Active Learning, 3 (2018), 58-64

Altun, Mustafa, 'The Effects of Teacher Commitment on Student Achievement', International Journal of Social Sciences \& Educational Studies, 3 (2017)

Gull, Fariha, and Shumaila Shehzad, 'Effects of Cooperative Learning on Students' Academic Achievement', Journal of Education and Learning, 9 (2015), 246-55

Haseena, V. A, and Ajims. P Mohammed, 'Aspects of Quality in Education for the Improvement of Educational Scenario', Journal of Education and Practice, 6 (2015), 100-106

Juščáková, Zuzana, '5 Th International Conference for Theory and Practice in Education Information and Education', in 5th International Conference for Theory and Practice in Education Information and Education, 2012

Juste, Margarita Pino, and Beatriz Rodríguez López, 'Learning Strategies in Higher Education', International Journal of Learning, 17 (2010), 259-74

Kistner, Saskia, Katrin Rakoczy, Barbara Otto, Eckhard Klieme, and Gerhard Büttner, 'Teaching Learning Strategies. The Role of Instructional Context and Teacher Beliefs', Journal for Educational Research Online, 7 (2015), 176-97

Mart, Çağrı Tuğrul, 'A Passionate Teacher: Teacher Commitment and Dedication to Student Learning', International Journal of Academic Research in Progressive Education and Development, 2 (2013), 2226-6348

Mehra, Sanjay, 'Criteria of Quality School Education', 2018, 665-68

Olurotimi, Ogunlade Joseph, Kamonges Wahab Asad, and Abdulkadir Abdulrauf, 'Motivational Factors and Teachers Commitment in Public Secondary Schools in Mbale Municipality', Journal of Education and Practice, 6 (2015), 117-23

Panigrahi, Manas Ranjan, 'School Effectiveness at Primary Level of Education in Relation to Classroom Teaching', International Journal of Instruction, 7 (2014), 51-64

Senol, Hulya, and Gokmen Dagli, 'Increasing Service Quality in Education: Views of Principals and Teachers', Eurasia Journal of Mathematics, Science and Technology Education, 13 (2017), 4857-71 
Shi, Hong, 'Learning Strategies and Classification in Education', Institute for Learning Styles Journal, 1 (2017), 24-36

Széll, Krisztián, 'Factors Determining Student Achievement', Hungarian Educational Researcch Journal, 3 (2013), 55-66

Werang, Basilius Redan, and Anak Agung Gede Agung, 'Teachers' Job Satisfaction, Organizational Commitment, and Performance in Indonesia: A Study from Merauke District', International Journal of Development and Sustainability, 6 (2017), 700-711 